\title{
Psychological effects of sodium valproate and carbamazepine in epilepsy
}

\author{
G Stores, P L Williams, E Styles, Z Zaiwalla
}

\begin{abstract}
Information from standardised tests of intelligence, school attainments, attention, memory and visuomotor function, together with parent and teacher questionnaire information about various aspects of behaviour, was obtained for 63 schoolchildren with newly diagnosed epilepsy before treatment with sodium valproate or carbamazepine, and again at intervals for a total period of 12 months. The same information was collected on 47 matched controls. The children with epilepsy represented those under non-specialised paediatric care.

The result showed that both drugs were effective in most cases at modest dosage without causing notable psychological effects 12 months into treatment. Modest and temporary adverse cognitive effects seen earlier in treatment could have been the result of uncontrolled seizure discharge. Improved function was the same in children with epilepsy and controls. Some psychological abnormalities in the children with epilepsy were evident before treatment suggesting early unwanted effects of the epileptic process itself.
\end{abstract}

(Arch Dis Child 1992;67:1330-7)

The possible psychological effects of antiepileptic drugs have been studied since at least the 1950 s but interest in this area of inquiry has increased considerably in the last 15 years or so, with published accounts about antiepileptic medications old and new. Of particular interest to paediatricians are the reports concerning sodium valproate and carbamazepine which, at least in the UK, have largely replaced phenobarbitone and phenytoin as the drugs of choice for treating epilepsy in children. Both these treatments have acquired the reputation of being effective in suppressing seizures, generally without causing harm unless given in very high dosage.

However, this reputation and, indeed, information about the psychological effects of other antiepileptic drugs, is mainly based on findings from studies of uncertain relevance to general, non-specialised paediatric practice (for review see Hirtz and Nelson ${ }^{1}$ ). Most investigations have been conducted on adult patients with complicated epilepsies or on normal adult volunteers. Patients studied have sometimes been taking multiple drug treatments or have been mixed regarding intellectual level and age, causing further difficulties in the interpretation of the findings. The psychological assessments employed have usually varied considerably from one study to another and have also frequently been questionable in other ways. Sometimes they have consisted of no more than impressions, and when laboratory (including computerised) measurements have been used, the relationship of such procedures to performance and behaviour in real life situations has not been demonstrated. Very few studies have established pretreatment baselines before assessing treatment over a sufficient period of time to allow possible short and long term effects to be detected. Other requirements not usually observed are the need in longitudinal studies of children to use carefully chosen controls in order to assess developmental influences and, as the effectiveness (or lack of it) of treatment on seizure occurrence may itself have psychological effects, the importance of taking seizure frequency into account over the period of study.

The present study was designed with these various issues in mind in order to make the findings and their implications for clinical practice easier to understand. The focus of the study was not children with epilepsy attending special epilepsy services but those under the care of their local paediatrician, and attending mainstream school. Therefore the children represented those with the more typical and milder forms of seizure disorder, taking treatment characteristically that employed within general non-specialist paediatric practice.

\section{Methods}

OVERALL DESIGN

This was a prospective study, over a 12 month period, in which repeated psychological assessments were made on a series of children with newly diagnosed epilepsy before the introduction of a single antiepileptic drug, and then repeated at intervals after the start of treatment. Regarding treatment effects, therefore, the children acted as their own controls over the course of the study. In addition, however, assessments were made of a group of matched non-epileptic children in order to assess practice effects on repeated testing, the effects of special attention given to them during the investigation, and developmental effects over the course of the study. Controls within the epilepsy group by matching for seizure frequency or abundance of seizure discharge were, or course, not possible because of the unpredictability of response to treatment and, in any case, the unfeasibility of trying to assess these seizure variables in this setting other than by ordinary clinical means. 
SUBJECTS

At our request paediatric colleagues notified us of children whom they had recently diagnosed as suffering from epilepsy and whom they intended to treat with sodium valproate or carbamazepine. For these purposes epilepsy implied the occurrence of at least two seizures of primary cerebral origin. Sixty three children were recruited who met the additional following criteria: (1) age between 7 and 12 years inclusive; (2) attending mainstream school with English as their first language; and (3) absence of gross neurological or psychiatric disorder, other serious chronic illness, or the need for long term treatment with other drugs.

These restrictions allowed psychological measurement to be kept uniform and possible confounding effects of low intelligence, cultural differences, or other serious disorder to be avoided. No attempt was made to influence the paediatricians' choice of antiepileptic drug treatment or any other aspect of management. All children with epilepsy remained exclusively under the care of their local paediatric service for the duration of the study.

A control group of non-epileptic children was identified as follows. As far as possible each child with epilepsy was matched with a nonepileptic child from the same class at school (to control for teacher differences and/or changes of teacher), of the same sex and age, and of the same overall attainments level as judged by the class teacher. Obvious differences in socioeconomic background were avoided. The original intention was to match every child with epilepsy with a non-epileptic control but this proved impossible in 16 of the 63 cases mainly because parents did not want the school to know that their child had epilepsy, but also because a few schools were so small that a close match for sex, age, and attainment was not possible.

The parents of the patients for possible inclusion in the study and possible control children had been approached by letter with an explanation of the purpose and nature of the study and an invitation for their children to take part. Informed written consent was obtained from the parent or guardian of each child entered into the study. The study was approved by the local research ethics committee.

\section{ASSESSMENTS}

\section{(1) Psychological assessments}

These were carefully selected with the intention of covering a range of cognitive functions and behaviours. A combination was employed of formal testing of general intelligence and attainments, measures of specific cognitive abilities, and questionnaire ratings of behaviour by parents and teachers. All assessments were carried out by a psychologist experienced in working with children and their families.

Table 1 describes the assessments of cognitive function that were employed. These consisted of general tests and specific ability tests. The general tests were given before treatment was started and again at 12 months after the introduction of treatment. These tests were not considered sensitive to subtle psychological changes but were used to screen out children of low intelligence within the mainstream school population and to detect any gross changes of cognitive function over the 12 months period of the study. The specific ability tests were given before the start of treatment and at one, three, six, and 12 months after treatment had been introduced. They were designed to show possible drug effects and can be categorised as tasks involving aspects of attention, memory, and visuomotor function. These tests are described further in the appendix.

In a preliminary phase of the study, a number of specific ability tests were administered to normal children. Only those with minimal overlap with other measures and satisfactory test-retest reliability (shown in the appendix) were retained. The tests used were also designed to be enjoyable in order to prevent children dropping out of the testing sessions. The cognitive function tests were administered at the same time of day to each child with epilepsy and control child as far as possible.

The measures of behaviour that were used are listed in table 2. The Conners scales are well established and researched measures of a range of clinically important aspects of childhood behaviour. The cognitive function questionnaire was developed for use in studies of the behaviour at school of children with epilepsy. The derivation of this measure for use with teachers, and the aspects of behaviour at school, are very

Table 1 Tests of cognitive function

\begin{tabular}{|c|c|}
\hline Test & Functions assessed \\
\hline $\begin{array}{l}\text { General tests: } \\
\text { Abbreviated form of WISC-R }\end{array}$ & $\begin{array}{l}\text { Verbal IQ; performance IQ, } \\
\text { overall IQ"* }\end{array}$ \\
\hline $\begin{array}{l}\text { Neale Analysis of Reading } \\
\text { Ability }^{3}\end{array}$ & $\begin{array}{l}\text { Reading rate, accuracy and } \\
\text { comprehension }\end{array}$ \\
\hline $\begin{array}{l}\text { British Ábility Scale arithmetic } \\
\text { test }^{4}\end{array}$ & Arithmetic attainments \\
\hline \multicolumn{2}{|l|}{$\begin{array}{l}\text { Specific ability tests (see } \\
\text { appendix for further details): }\end{array}$} \\
\hline Cancelling test & Establishing an attentional set \\
\hline Focal attention test & $\begin{array}{l}\text { Focusing attention in presence } \\
\text { of distracters }\end{array}$ \\
\hline Sustained attention test & $\begin{array}{l}\text { Maintaining attention during } \\
\text { long monotonous task }\end{array}$ \\
\hline Memory for stories & $\begin{array}{l}\text { Memory beyond short term } \\
\text { span for meaningful material }\end{array}$ \\
\hline Pegboard & Visuomotor coordination \\
\hline Digit symbol substitution test & $\begin{array}{l}\text { Attention, visual search } \\
\text { memory, and visuomotor } \\
\text { coordination }\end{array}$ \\
\hline
\end{tabular}

Table 2 Measures of behaviour

\begin{tabular}{|c|c|}
\hline Measure & Behaviours assessed \\
\hline $\begin{array}{l}\text { Conners Parents' } \\
\text { Questionnaire (see Barkley }{ }^{5} \text { ) }\end{array}$ & $\begin{array}{l}\text { Anxiety } \\
\text { Conduct problems } \\
\text { Impulsivity/hyperactivity } \\
\text { Learning problems } \\
\text { Psychosomatic problems } \\
\text { Obsessionality } \\
\text { Antisocial behaviour } \\
\text { Restlessness/disorganisation }\end{array}$ \\
\hline $\begin{array}{l}\text { Conners Teacher Questionnaire } \\
\left(\text { (see Barkley }{ }^{5}\right)\end{array}$ & $\begin{array}{l}\text { Anxiety } \\
\text { Conduct problems } \\
\text { Inattention } \\
\text { Overactivity }\end{array}$ \\
\hline $\begin{array}{l}\text { Cognitive Function } \\
\text { Questionnaire }^{6} \text { (for teachers) }\end{array}$ & $\begin{array}{l}\text { Distractibility } \\
\text { Drowsiness } \\
\text { Fear of failure } \\
\text { Memory } \\
\text { Social isolation }\end{array}$ \\
\hline
\end{tabular}


different from that of the Conners teacher questionnaire.

From the information given in the published accounts of these assessments, they all appeared to be psychometrically acceptable. These measures were taken, in the case of children with epilepsy, before antiepileptic drug treatment was started and then repeated at one, three, six, and 12 months after treatment had begun. They were taken at the same point in time as far as possible for each child with epilepsy and control child.

\section{(2) Assessment of seizure disorder and its treatment} Each epileptic child's type of seizure disorder was determined mainly on the basis of the clinical features of the attacks (as recorded by the paediatrician) and results of electroencephalography (EEG). Guidelines were provided to paediatricians emphasising the need for a detailed description of the attacks from the first subjective or objective change to the child's complete recovery, and the circumstances in which the attacks occurred. EEG assessment consisted of at least a standard recording (including overbreathing and photic stimulation phases) and in some cases a sleep deprivation/ natural sleep recording. No structural cerebral lesion was detected in any of the children during the course of the study.

Seizure frequency was judged principally by means of a diary record completed each day by parents or other observers. Date, time, and type of attack was recorded in this way.

Table 3 Numbers of children in epilepsy and control groups according to treatment and sex

\begin{tabular}{lllllc}
\hline Sex & $\begin{array}{l}\text { Children with } \\
\text { epilepsy }\end{array}$ & $\begin{array}{l}\text { Sodium } \\
\text { valproate }\end{array}$ & Carbamazepine & Controls & Total \\
\hline Boys & 34 & 20 & 14 & 26 & 60 \\
Girls & 29 & 14 & 15 & 21 & 50 \\
Total & 63 & 34 & 29 & 47 & 110 \\
\hline
\end{tabular}

Table 4 Mean ages (in years) of children with epilepsy and controls by treatment group and sex

\begin{tabular}{lccllr}
\hline Sex & $\begin{array}{l}\text { Children with } \\
\text { epilepsy }\end{array}$ & $\begin{array}{l}\text { Sodium } \\
\text { valproate }\end{array}$ & Carbamazepine & Controls & Total \\
\hline Boys & $9 \cdot 68$ & $9 \cdot 68$ & $9 \cdot 67$ & $10 \cdot 10$ & $9 \cdot 86$ \\
Girls & 10.02 & 10.67 & $9 \cdot 41$ & 10.08 & 10.05 \\
All & 9.83 & 10.09 & $9 \cdot 54$ & 10.09 & 9.94 \\
\hline
\end{tabular}

Table 5 Types of seizure and drug prescribed

\begin{tabular}{|c|c|c|c|c|}
\hline $\begin{array}{l}\text { Seizure type } \\
\text { (overall category) }\end{array}$ & $\begin{array}{l}\text { More specific } \\
\text { seizure type }\end{array}$ & $\begin{array}{l}\text { Sodium } \\
\text { valproate }\end{array}$ & Carbamazepine & Total \\
\hline Absences & & 11 & 2 & 13 \\
\hline $\begin{array}{l}\text { Other primary } \\
\text { Generalised }\end{array}$ & $\begin{array}{l}\text { Tonic-clonic } \\
\text { Myoclonic } \\
\text { Subtotal }\end{array}$ & $\begin{array}{r}2 \\
17 \\
19\end{array}$ & $\begin{array}{l}1 \\
8 \\
9\end{array}$ & $\begin{array}{r}3 \\
25 \\
28\end{array}$ \\
\hline Partial & $\begin{array}{l}\text { Complex partial } \\
\text { Benign centrotemporal } \\
\text { Partial with secondary } \\
\text { generalisation } \\
\text { Uncertain type } \\
\text { Subtotal }\end{array}$ & $\begin{array}{l}2 \\
0 \\
1 \\
0 \\
3\end{array}$ & $\begin{array}{r}5 \\
4 \\
7 \\
7 \\
2 \\
18\end{array}$ & $\begin{array}{r}7 \\
4 \\
8 \\
2 \\
21\end{array}$ \\
\hline Unclassifiable & & 1 & 0 & 1 \\
\hline Total & & 34 & 29 & 63 \\
\hline
\end{tabular}

Compliance with drug treatment prescriptions was assessed from the plasma drug level determinations made routinely in the paediatric outpatient clinics.

Any unwanted effects reported by the children with epilepsy or their parents were recorded by paediatricians to whom a list of possible adverse effects was provided by the investigators as a guide, although additional items were added to this list as necessary.

\section{ANALYSIS}

For analysis of the data the following groupings were used: all children with epilepsy on either sodium valproate or carbamazepine, children with epilepsy taking sodium valproate only, children with epilepsy taking carbamazepine only, non-epileptic control children, boys, and girls.

All pretreatment data was converted to adjusted means using covariate analysis where necessary to compensate for sex dependency. All results during treatment were calculated as percentage changes from pretreatment values for each group, using covariate analysis to correct for pretreatment differences between groups and any sex dependence.

Differences between control and treatment groups, the two treatment groups, and male and female groups were analysed using Students' $t$ test. This test was also used to detect significant differences between the control group and the two drug groups separately.

In a few cases the first prescribed drug failed to change seizure frequency and the paediatrician then prescribed the other drug. In these cases, only data collected while the child was taking the first drug were analysed.

\section{Results}

(1) GENERAL CHARACTERISTICS OF THE GROUPS STUDIED

A total of 110 children were included in the study: 63 children with epilepsy and 47 controls. There were no withdrawals during the course of the investigation.

The numbers of children in the epilepsy and control group according to treatment and sex are shown in table 3 . There were slightly more boys than girls on treatment and in the trial as a whole, but overall there were no significant differences regarding sex ratios. Table 4 shows the mean ages of the children, by treatment group and sex. Again, there were no statistically significant differences.

For the group of children with epilepsy, the types of seizure and prescribed drugs are shown in table 5. A wide range of seizure types was seen. In general, paediatricians had prescribed sodium valproate for primary generalised seizures (with the exception of two children with absence epilepsy for whom carbamazepine was used), whereas mainly carbamazepine had been prescribed for the treatment of partial seizures.

(2) COMPLIANCE AND SEIZURE CONTROL Paediatric notes, including the results of plasma 
drug concentration determinations, indicated that no problems of compliance were encountered. The dosages used were modest: up to $30 \mathrm{mg} / \mathrm{kg}$ of body weight/day of sodium valproate, and up to $20 \mathrm{mg} / \mathrm{kg}$ of body weight/ day of carbamazepine. These dosages gave plasma concentrations in the lower part of the 'therapeutic range' and achieved complete or almost complete control of seizures in $79 \cdot 7 \%$ of patients, usually within the first three months of treatment, with no difference between sodium valproate and carbamazepine in this respect.

\section{(3) UNWANTED DRUG EFFECTS}

A total of 28 unwanted effects of antiepileptic drug treatment were recorded in the paediatric notes of 27 children. These are shown in table 6. Drowsiness was the most commonly reported problem and was described in four children from each drug treatment group. There was no report of intoxication or any serious adverse effect in any child.

\begin{tabular}{|c|c|c|}
\hline Side effect & $\begin{array}{l}\text { Sodium } \\
\text { valproate }\end{array}$ & Carbamazepine \\
\hline $\begin{array}{l}\text { Drowsiness } \\
\text { Weight increase }\end{array}$ & 4 & 4 \\
\hline $\begin{array}{l}\text { Weight increase } \\
\text { Diplopia }\end{array}$ & 3 & $\sqrt{3}$ \\
\hline Rash & - & 2 \\
\hline Nausea & 2 & - \\
\hline Vomiting & 1 & 1 \\
\hline Increased appetite & 1 & 1 \\
\hline Ataxia & - & 1 \\
\hline Abdominal pain & 1 & - \\
\hline Hyperactive & 1 & - \\
\hline $\begin{array}{l}\text { Tremor } \\
\text { Headache }\end{array}$ & 1 & $\overline{1}$ \\
\hline $\begin{array}{l}\text { Headache } \\
\text { Gastric problem }\end{array}$ & - & 1 \\
\hline Total & 14 & 14 \\
\hline
\end{tabular}

Table 7 Significantly poorer pretreatment scores on specific ability tests of each seizure type group compared with controls

\begin{tabular}{ll}
\hline Seizure type & Test \\
\hline Absence $(\mathrm{n}=13)$ & Pegboard $^{* *}$ \\
$\begin{array}{c}\text { Other primary generalised } \\
(\mathrm{n}=28)\end{array}$ & Pegboard $^{* *}$ \\
Partial $(\mathrm{n}=2.1)$ & Digit symbol $^{*}$ \\
& $\begin{array}{l}\text { Cancelling } \\
\text { Focal attention }\end{array}$ \\
& $\begin{array}{l}\text { Pegboard } \\
\text { Digit symbol }\end{array}$ \\
\hline${ }^{*} \mathrm{p}<0.05,{ }^{* *} \mathrm{p}<0.01$ &
\end{tabular}

Table 8 Differences in specific ability test results between each treatment group and controls for each time of assessment after introduction of treatment

\begin{tabular}{|c|c|c|}
\hline $\begin{array}{l}\text { Time of assessment after introduction of } \\
\text { treatment (months) }\end{array}$ & $\begin{array}{l}\text { Treatment group } \\
\text { (worse than controls } \\
\text { in all cases) }\end{array}$ & Test \\
\hline 1 & $\begin{array}{l}\text { Sodium valproate } \\
\text { Carbamazepine }\end{array}$ & $\begin{array}{l}\text { Focal attention } \\
\text { Pegboard }\end{array}$ \\
\hline 3 & $\begin{array}{l}\text { Sodium valproate } \\
\text { Carbamazepine }\end{array}$ & $\begin{array}{l}\text { Cancelling } \\
\text { Digit symbol } \\
\text { Pegboard" }\end{array}$ \\
\hline 6 & $\begin{array}{l}\text { Sodium valproate } \\
\text { Carbamazepine }\end{array}$ & $\begin{array}{l}\text { Digit symbol } \\
\text { Sustained attention }\end{array}$ \\
\hline 12 & $\begin{array}{l}\text { Sodium valproate } \\
\text { Carbamazepine }\end{array}$ & $\begin{array}{l}\text { Focal attention } \\
\text { Sustained attention }\end{array}$ \\
\hline
\end{tabular}

${ }^{*} \mathbf{p}<0.05,{ }^{* *} p<0 \cdot 01$.

\section{(4) GENERAL TESTS OF INTELLIGENCE AND}

\section{ATTAINMENTS}

(a) Pretreatment

When the mean scores of all children in the study on the tests of general intelligence and educational attainments were calculated it was found that boys scored significantly higher than girls on the verbal and non-verbal intelligence quotient (IQ) sections of the Wechsler Intelligence Scale for Children-Revised (WISC-R) $(p<0.01$ in each case) and also obtained higher scores on the Neale reading rate and comprehension tests $(p<0.05$ in each case). These sex differences were taken into account by the use of covariate analysis when comparisons were made between epileptic and control groups.

No significant differences were seen in comparisons between the three overall categories of seizure type compared with each other and with controls. All these groups showed no significant difference from each other regarding mean age.

With the mean values adjusted by covariate analysis for sex differences, no significant differences were seen in comparisons between controls and any of the groups subsequently given antiepileptic drug treatment (sodium valproate, carbamazepine, either group) for WISC-R verbal or performance IQs, Neale reading ability scores or the British Ability Scales arithmetic score. This close correspondence demonstrated the accuracy with which teachers had matched epileptic children and their controls for educational attainments.

\section{(b) After 12 months of drug treatment}

No significant differences were seen in any comparison between any treatment group and controls for any of the measures of general intelligence or attainments.

\section{(5) SPECIFIC ABILITY TESTS \\ (a) Pretreatment}

No significant differences between boys and girls were seen in any of these tests.

Compared with controls, each overall seizure type group showed significantly poorer scores on various specific ability tests. These findings are summarised in table 7 . Children with epilepsy consistently showed poorer visuomotor coordination irrespective of type of epilepsy, whereas aspects of attention were more characteristic of the partial group. In no test did children with epilepsy score significantly better than controls.

There were no significant differences between the different subsequently treated groups and controls.

\section{(b) Changes during treatment}

Table 8 shows tests on which one or other of the treatment groups were significantly different from the controls at each assessment after the introduction of antiepileptic drug treatment. In all instances the performance of the treatment group was worse than that of controls. In general, the sodium valproate and carbamazepine groups did not differ greatly in the few 
significant differences seen between each of them and controls. Attentional differences were more consistently seen throughout the repeated assessments, lower focal attention scores characterising the sodium valproate group and lower sustained attention scores the carbamazepine group. In addition, poorer performance than controls was seen in the pegboard measure of visuomotor coordination early in treatment with carbamazepine, and on the more complex digit symbol task during the middle phase of the 12 month period of treatment with sodium valproate.

\section{(6) MEASURES OF BEHAVIOUR}

\section{(a) Pretreatment}

No significant differences between boys and girls were seen on any of these measures. Table 9 shows the significant differences that were found between the different seizure type groups and control children. In all differences the epilepsy group score higher than controls.

Collectively, the children with epilepsy showed many significantly worse behaviours compared with controls. A common thread throughout was various aspects of poor attention and 'drowsiness' according to teachers, but in general the absence and partial seizure groups displayed a greater variety of disturbance than the other primary generalised group, sharing a higher level of impulsive/hyperactive and memory problems, as judged by teachers,

Table 9 Pretreatment behavioural differences between each seizure type group and control children

\begin{tabular}{|c|c|c|}
\hline Seizure type & Questionnaire & Factor \\
\hline \multirow[t]{2}{*}{ Absence $(n=13)$} & Conners Parents' Questionnaire & $\begin{array}{l}\text { Conduct problems* } \\
\text { Impulsivity/hyperactivity } \\
\text { Learning problems*: } \\
\text { Muscular tension*: }\end{array}$ \\
\hline & $\begin{array}{l}\text { Conners Teacher Questionnaire } \\
\text { Cognitive Function Questionnaire }\end{array}$ & $\begin{array}{l}\text { Inattention* } \\
\text { Distractibility* }^{*} \\
\text { Drowsiness }^{* *} \\
\text { Memory problems }\end{array}$ \\
\hline $\begin{array}{l}\text { Other primary generalised } \\
(\mathrm{n}=28)\end{array}$ & Cognitive Function Questionnaire & Drowsiness* \\
\hline \multirow[t]{2}{*}{ Partial $(n=21)$} & Conners Parents' Questionnaire & $\begin{array}{l}\text { Impulsivity/hyperactivity: } \\
\text { Psychosomatic }\end{array}$ \\
\hline & Cognitive Function Questionnaire & $\begin{array}{l}\text { Distractibility* } \\
\text { Drowsiness":* } \\
\text { Fear of failure } \\
\text { Memory problems }\end{array}$ \\
\hline
\end{tabular}

p $<0.05, * * p<0.01$. compared with their controls. When the groups subsequently treated with sodium valproate or carbamazepine were compared with controls no significant pretreatment differences were seen.

\section{(b) Changes during treatment}

Table 10 shows the relatively few significant differences in behaviour scores between each treatment group and control children during the course of treatment. No consistent, meaningful pattern is seen up to the six month assessment (with the anomalous result that at three and six months into treatment the children with epilepsy treated with carbamazepine had lower inattention scores than controls), and at 12 months of treatment no differences at all were found.

\section{Discussion}

This study was essentially concerned with sodium valproate and carbamazepine as typically used in general paediatric practice. The main findings were that these drugs were equally effective in producing seizure control without common serious adverse physical complications, and that they were also equivalent in being associated with no reduction in intelligence and school attainments over the first 12 months of treatment. Children taking either type of medication showed inferior scores on various tests of specific cognitive ability, mainly those involving aspects of attention, over the 12 month period. In contrast, no behavioural differences between treated children with epilepsy and their controls were found after 12 months of treatment and at earlier stages of treatment only a few inconsistent differences of uncertain significance. It is possible that, in any case, these differences between the children with epilepsy and their controls were not drug effects at all but the result of remaining overt seizures or subtle seizure discharge both of which are capable of producing psychological effects. $^{7}$

A main concern in the design of the study was to study schoolchildren with epilepsy in the community under the care of the local paediatric services - that is representative of children with epilepsy in general rather than those attending special clinics or services because of the severity of their disorder. The types of epilepsy exhibited by the children studied and the high rate of response to antiepileptic treatment both indicate the representative nature of the sample

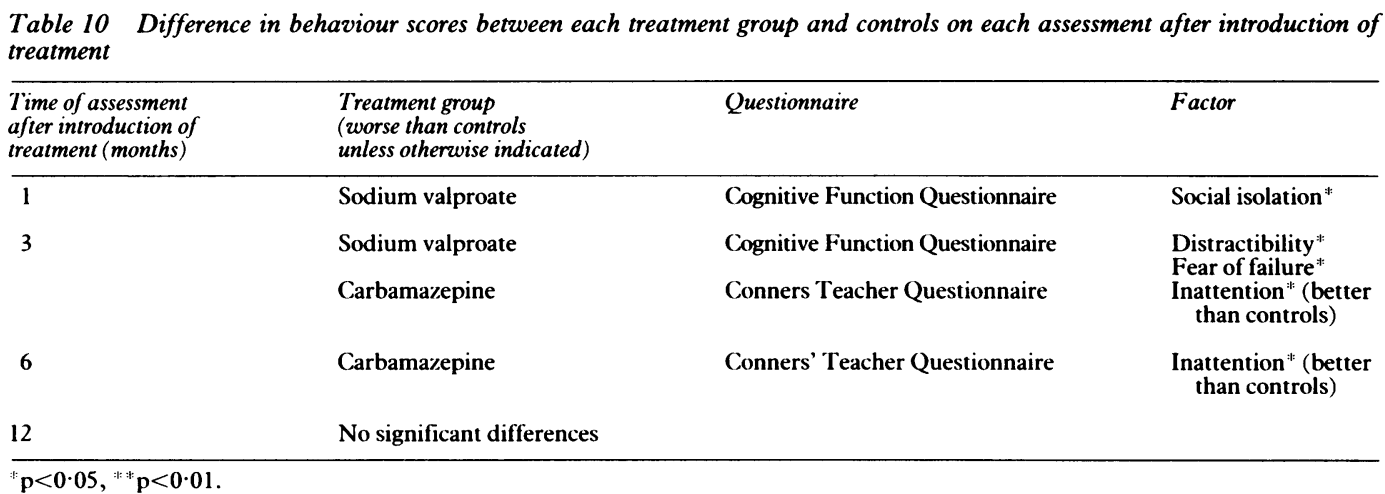


obtained. A basic principle was to avoid interfering with paediatricians' usual practice for the purpose of the study. Ethics approval was based on that understanding. In particular, random assignment of the children to treatment with either sodium valproate or carbamazepine was not considered justifiable. This would have especially been so in the case of absence epilepsy (13 of the 63 children with epilepsy) for which carbamazepine is acknowledged to be ineffective and sometimes harmful. The difficulties in obtaining matched controls for all the children with epilepsy were unsurmountable in the circumstances. However, inclusion of a comparison group of normal children was essential to control for developmental changes and other possible explanations of improvements over the course of the study.

The psychological measures used in this study were carefully selected and the repeat reliabilities of the specific ability tests specially assessed before the study to ensure that the tests were satisfactory in this respect. The repeated assessment procedures, and the test battery, proved acceptable to children, parents and teachers; no child was withdrawn during the study. The psychological assessments before the start of treatment were of particular importance in providing baselines with which later assessments could be compared, but also in identifying pretreatment differences in intelligence and attainment between boys and girls, and the behavioural differences between the normal control children and those with epilepsy before their treatment was started. These differences indicated the need for statistical adjustment to make later comparisons valid.

These pretreatment differences between the children with epilepsy and their controls are of considerable interest in themselves, especially in view of the differences in this respect between the main overall types of epilepsy. The partial seizures subgroup displayed the greatest variety of differences regarding specific abilities, whereas most behavioural differences were seen in the children with absence seizures followed by the partial seizures subgroup. There is no clear separation between these subgroups regarding particular types of differences from controls. Perhaps the most consistent element throughout these differences in the results of specific ability testing and behavioural ratings by both parents and teachers is inattentiveness of one sort or another. The differences in this respect (obviously not attributable to treatment in this instance) are in keeping with the general tendency for children with epilepsy to be considered 'inattentive', ${ }^{8}$ including being perceived by their teachers as having poor concentration and mental processing and being less alert than their non-epileptic peers even when matched for overall school attainment level. ${ }^{6}$ In the last mentioned study, children with a past history of epilepsy but no longer taking antiepileptic drugs because of apparent remission of their seizures, were still considered by their teachers to be less alert than their nonepileptic counterparts. The possibility exists that some children with epilepsy, irrespective of type, have a form of attentional disorder, related to impaired alertness, to which untreated seizures and some form of treatment can make a contribution, but which is not wholly explicable in these terms. The idea of an attentional deficit persisting in between seizures is not new. Mirsky and van Buren suggested this some time ago, at least in the case of absence seizures. ${ }^{9}$

It is interesting that the reassuring results for both drugs used in the present study are generally mirrored in studies of adult patients taking either sodium valproate or carbamazepine singly (for example see Gillham et $a l^{10}$ ). However, because of the complexities of trying to compare findings on patient groups of widely different ages, types of epilepsy, and other possible determinants of behavioural outcome, the present discussion is confined to other studies of children.

Comparisons between the findings in the present study and other reports concerning children is itself difficult enough in view of differences in study design. The nearest comparison is that with the study by Forsythe et al in which 64 children with newly diagnosed tonic-clonic or partial seizures (age 5 to 14 years) were randomly assigned to treatment with carbamazepine, phenytoin, or sodium valproate. ${ }^{11}$ The children were assessed prospectively over a 12 month period on a range of cognitive function tests that were mainly concerned with visual or auditory memory but that also included tests of vigilance, concentration, and speed of information processing. None of these measures were the same as those used in the present study apart from additional measures of intelligence and reading (but only taken after the start of treatment) and no standardised assessments of behaviour were employed. Assessments were performed before treatment and at intervals of one, six, and 12 months after the start of treatment. A fifth of the original sample were lost to the study but in the remainder seizures were controlled in every case. A control group contained 31 children with nocturnal enuresis and nine with migraine. Analysis of the findings was limited for a variety of reasons and the main effect reported was an association between carbamazepine treatment (at modest dosage) and impairment at six and 12 months on a composite measure of memory function. As no pretreatment measures of intelligence and school attainments were made, the relevance of this memory deficit to more global measures, including educational attainment, remains unclear.

The results of other studies of children taking sodium valproate or carbamazepine as single treatments are generally difficult to interpret. Herranz et al reported various adverse behavioural effects in $64 \%$ of children after the introduction of sodium valproate, but the assessments used in this study were not psychometrically evaluated and did not include pretreatment measures. ${ }^{12}$ In addition the children studied were mixed regarding severity of seizure disorder and intelligence and the body weight related dosage varied widely. Silverstein $e t a l$, in another uncontrolled study, reported a wide range of adverse behavioural effects after treatment with carbamazepine but 
some of the same criticisms apply to this report and its lack of detail makes evaluation difficult. ${ }^{13}$ Schain et al demonstrated attentional and perceptual improvements at four to six months of carbamazepine treatment compared with previous treatment with sedative type antiepileptic drugs ${ }^{14}$; clearly, the design and permissable conclusions from this study are very different from those of the present investigation. In the study by Jacobides improvements in arithmetic were reported over a year in $22 \%$ of children after treatment with carbamazepine and in $35 \%$ maladjustment ratings were said to fall. ${ }^{15}$ Other improvements reported in this account were increases in IQ and greater alertness. Unfortunately, evaluation of these claims is hampered by lack of detail and the absence of controls. Part of a complex study reported by Trimble and Cull consisted of the comparison of small groups of children with epilepsy taking either sodium valproate or carbamazepine. ${ }^{16}$ Significantly better reaction times and scores on various cognitive tests were reported in children taking carbamazepine compared with those on sodium valproate. The report by Aman et al that cognitive function measures were best shortly after taking carbamazepine (near peak concentration) raises unanswered questions about the factors mediating such drug effects. ${ }^{17}$

These reports concerning children provide additional evidence of the inconsistent results of studies of the psychological effects of antiepileptic drugs, and the difficulties of interpreting the findings in view of various methodological designs and shortcomings, especially failures to control for relevant factors. No two studies are even remotely alike in the composition of the groups studied, the measures used, the attempt to control for developmental variables or the various factors, in addition to antiepileptic drug treatment, that influences cognitive or behavioural outcome. There is clearly a need to standardise assessment and procedures in future studies.

In the meantime, it seems safe to conclude that the weight of evidence is in favour of sodium valproate and carbamazepine deserving their reputation that, as typically used in paediatric practice, they are effective treatments that generally do not have adverse consequences of practical clinical significance.

We are most grateful to the children and parents who took part in this study and to the many paediatric colleagues who very kindly referred cases to us and also helped us with arrangements. We also thank Sanofi Labaz and Ciba Geigy for the financial assistance with the investigation and especially Dr Derrick Easter for his unfailing help and advice.

\section{Appendix: descriptions of specific ability tests}

CANCELLING TEST ${ }^{18}$

Measures ability to establish an attentional set and the rate at which this is established. There are five timed trials where the child cancels the letters among digits and a reverse category trial requiring cancellation of digits from among letters. This reverse category trial shows any difficulty in switching attentional set. Testretest reliability $0 \cdot 89$.
FOCAL ATTENTION TEST ${ }^{19}$

This provides a measure of the ability to focus attention on relevant items in the presence of distracters. The target is always an orange circle which is initially set among different colour circles and later among circles and squares. The number of distracters is increased over three trials. The child sorts the cards into those showing the targets and those without. Testretest reliability $0 \cdot 6$.

\section{SUSTAINED ATTENTION TEST ${ }^{20}$}

A measure of the ability to sustain attention during a monotonous task lasting just under 15 minutes. The child is asked to identify animal names among other words presented at a standard rate of one every 2 seconds. Test-retest reliability $0 \cdot 73$.

\section{MEMORY FOR STORIES ${ }^{21}$}

A measure of memory for meaningful material that exceeds the short term span. The stories have short episodes and little redundancy but the material must be interpreted and structured to be remembered well. Two stories are given at the start of the session for immediate recall. At the end of the session the children are assessed for delayed recall and comprehension questions are asked. Test-retest reliability $\mathbf{0 \cdot 6}$.

\section{PEGBOARD $^{22}$}

A measure of visuomotor coordination and fine hand control. Children are asked to insert a row of pegs using first the dominant hand and then the nondominant hand. Lastly a row of alternate colours is made using alternate hands. Testretest reliability $0 \cdot 6$.

\section{DIGIT SYMBOL SUBSTITUTION TEST}

This is a subtest from the WISC-R. It is a complex task involving attention, visual search memory and visuomotor coordination.

The above references describe versions of the tests which were either used or modified for use in the present study. All test-retest reliabilities were statistically significant.

1 Hirtz DG, Nelson KB. Cognitive effects of antiepileptic drugs. In: Pedley TA, Meldrum BS, eds. Recent advances in epilepsy number 2. Edinburgh: Churchill Livingstone, 1985: 161-81.

2 Wechsler D. Manual for the Wechsler intelligence scale for children—revised. New York: Psychological Corporation, 1974.

3 Neale MD. Analysis of reading ability. 2nd Ed. London: Macmillan, 1966.

4 Elliott CD. British ability scales. Introductory handbook. Windsor: National Foundation for Educational ResearchNelson, 1983

5 Barkley RA. Child behavior rating scales and checklists. In: Rutter M, Tuma AH, Lann IS, eds. Assessment and diagnosis in child psychopathology. London: Fulton, 1988:113-55.

6 Bennet-Levy J, Stores G. The nature of cognitive dysfunction in schoolchildren with epilepsy. Acta Neurol Scand 1984;69 in schoolchildren

7 Stores G. Electroencephalographic parameters in assessing the cognitive function of children with epilepsy. Epilepsia the cognitive function of

8 Stores G. Studies of attention and seizure disorders. Dev Med Child Neurol 1973;15:376-82.

9 Mirsky AF, van Buren JM. On the nature of the 'absence' in centrencephalic epilepsy; a study of some behavioral, 
electrocephalographic and autonomic factors. Electroelectrocephalographic and autonomic fact

10 Gillham RA, Williams N, Wiedmann KD Butler E, Larkin JG, Brodie MJ. Cognitive function in adult epileptic patients established on anticonvulsant monotherapy. Epilepsy Res 1990;7:219-25.

11 Forsythe I, Butler R, Berg I, McGuire R. Cognitive impairment in new cases of epilepsy randomly assigned to carbamazepine, phenytoin and sodium valproate. Dev Med Child Neurol 1991;33:524-34.

12 Herranz JL, Arteage R, Armijo JA. Side effects of sodium valproate in monotherapy controlled by plasma levels: a study of 88 pediatric patients. Epilepsia 1982;23:203-14.

13 Silverstein SS, Parish MA, Johnston MV. Adverse behavioral reactions in children treated with carbamazepine. $\mathcal{F}$ Pediatr reactions in child.

14 Schain RJ, Ward JW, Guthrie D. Carbamazepine as an anticonvulsant in children. Neurology 1977;27:476-80. 15 Jacobides GM. Alertness and scholastic achievement in young epileptics treated with carbamazepine. In: Meinardi $\mathrm{H}$,
Rowan AJ, eds. Advances in epileptology-1977: psychology, pharmacotherapy, and new diagnostic approaches. Amsterdam: Swets and Zeitlinger, 1977:114-9.
16 Trimble MR, Cull C. Children of school age: the influence of antiepileptic drugs on behaviour and intellect. Epilepsia 1988;29(suppl 3):S15-19.

17 Aman MG, Werry JS, Paxton JW, Turbott SH, Stewart AW. Effects of carbamazepine on psychomotor performance in children as a function of drug concentration, seizure type and time of medication. Epilepsia 1990;31:51-60.

18 Schiffrin RM, Schneider W. Controlled and automatic human information processing: II. Perception, learning, automatic attending, and a general theory. Psychol Rev 1977;84:127-90.

19 Treisman AM, Gelade G. A feature-integration of attention. Cognitive Psychology 1980;12:97-136

20 Gale A, Lynn R. A developmental study of attention. $\mathrm{Br} \mathcal{F}$ Educ Psychol 1972;42:260-6.

21 Glenn CG. The role of episodic structure and of story length in children's recall of simple stories. Fournal of Verbal Learming and Verbal Behavior 1978;17:229_A 7.

22 Costa LD, Vaughan HG Jnr, Levita E, Farber N. Purdue pegboard as a predictor of the presence and laterality of cerebral lesions. Fournal of Consulting Psychology 1963;27 133-7.

\section{Sisters of fragile $\mathrm{X}$ boys}

Inheriting the fragile $\mathrm{X}$ gene and showing the fragile $\mathrm{X}$ abnormality on cytogenetic analysis, it seems, are not the same thing. It is estimated that, of those who inherit the gene, about $80 \%$ of males and 50 to $60 \%$ of females show the chromosomal abnormality and develop the clinical syndrome. A recent study from Denver, Colorado (Randi J Hagerman and colleagues, Pediatrics 1992;89: 395-400) details the findings in the sisters of boys with the fragile $\mathrm{X}$ syndrome.

Thirty two fragile $\mathrm{X}$ girls were examined of whom 26 were sisters of an affected boy, three were cousins of such a boy, and three had presented because of their own problems and had no affected male relative. All were examined by the same person who was unaware of the cytogenetic findings. Eighteen chromosomally normal sisters of fragile $\mathrm{X}$ boys acted as the control group. The two groups of girls were assessed as regards physical features, intelligence, and behaviour.

On clinical examination six features were significantly more common in fragile $\mathrm{X}$ girls. They were prominent ears, a long face, shyness, poor eye contact, hand flapping, and hand biting. The control group had a mean IQ of 109 compared to 80 in the fragile $X$ girls of whom $53 \%$ had an IQ of less than 85 and $25 \%$ less than 70. Fragile $X$ girls with a normal overall IQ often had learning difficulty especially in mathematics. Ten in the fragile $X$ group but none in the control group satisfied criteria for the diagnosis of attention deficit hyperactivity disorder. They were usually impulsive and distractible with a short attention span rather than hyperactive. The authors report that many of the girls improved on treatment with either stimulant drugs or folic acid but they present no controlled data.

This study demonstrates the differences between the fragile $\mathrm{X}$ sisters of fragile $\mathrm{X}$ boys and their chromosomally normal sisters but it was not a population study and may not, therefore, give a complete picture of the possible range of findings in fragile $\mathrm{X}$ girls. 